\title{
Asymmetrical cross sections in historic riveted bridges
}

\author{
Philippe Van Bogaert*,a \\ ${ }^{a}$ Ghent University Dept. Civil Engineering, Belgium \\ philippe.vanbogaert@ugent.bemailto:
}

\begin{abstract}
The assessment of the load-carrying capacity of two steel bridges dating from 1907 and 1912, showed that most of the heavily loaded cross-sections were asymmetrical. The bridges are of the two-hinged portal frame type. Compared to simple beam bridges, portal frames with clamped or hinged supports allow redistribution of bending moments from the span centre towards the frame nodes. Consequently, the beam height at the span centre can be reduced, which is exactly what is needed for obtaining maximum vertical clearance of the subjacent waterway. Both bridges show heavy corrosion, some parts of the flanges and angle profiles of the end portals being seriously weakened. Full inventory has been made of the corrosion damage, as it appeared mostly in the edge frames of both structures. Reduction or suppressing of flanges has been introduced in the FEmodels of both bridges to assess the remaining load-carrying capacity for real traffic loading.

A particular characteristic are the asymmetrical cross-sections of the main portal frames. Because of this, the compression and tensile stresses in both flanges are of unequal magnitude, favouring the latter. The reason for this became evident rather quickly. In tensile parts of the riveted structure, weakening of cross-sections by holes has been taken into account, whereas it is not considered in compressed areas. Older standards and literature confirm the fact that this was allowed at the time riveted structures were still being built.

As today little is known about riveting, it was felt that this needed further underpinning. Apart from the longitudinal effects, lateral shrinkage of rivets during placing and plastic deformation also exist within the holes. The plastic deformation in the hole introduces a high compression between the rivet and the hole edge. As the heated rivet is cooling down and before further shrinking of the rivet diameter, this pressure must be reversed. Hence, cooling does not reduce the rivet diameter entirely, a portion being used to decompress the connection. Approximations of the process have been worked out and showed that the final reduction of the rivet section is less than the tolerance for fitting bolts. Hence, the assumptions made in the past may be underpinned to a certain extent.

This surely was resourceful during assessment of historic structures, requiring considerably more detailed numerical modelling than new structures, thus having better chances to preserve these valuable bridges for continuing use.
\end{abstract}

Keywords: riveted structures, historic bridges, load-carrying capacity, corrosion damage.

\section{INTRODUCTION}

Bridges can be qualified as historic for several reasons. Certainly, landmark structures may be recognised by the public for the quality of form and design, or by the fact that they have altered the character of their surroundings in a decisive manner [1]. Another reason may be that they demonstrate the application of new materials and construction processes as well as original craftsmanship. The latter certainly applies to the portal frame bridges across river Lys and the canal to Bruges in the city of Ghent.

In the following, two of these bridges are being considered. They were built respectively in 1907 and 1912, replacing movable swing bridges, narrowing the passage of vessels and causing interruption of road traffic during opening. Their construction fitted within the renewal of large parts of the city in view of the 1913 world exposition in Ghent. In that period, more precisely from 
1901, the Siemens-Martin and Thomas fabrication processes of steel had been developed and all data point towards the material being early age steel [2].

In addition, the portal frame structure allows maximizing the vertical clearance for waterway traffic, by redistributing bending moments from the central part of the span towards the frame nodes. This has been pushed far in the case of the Saint-George Bridge, presented further.

Since these bridges are applications of early age steel and riveted construction, they have become typical for the city and the general feeling is that they should be preserved as heritage objects. This also requires that the structural purpose is maintained and continue to carry local road traffic. Hence, the load-carrying capacity had to be verified, in spite of the fact that at the time of construction, design loads were considerably smaller than today. During this verification, the character of some cross sections, especially in the central part of the spans, were found to be highly asymmetrical. The latter lead to the main topic developed hereafter and related to the design of riveted structures.

\section{CONDITION OF 3 PORTAL FRAME BRIDGES}

\subsection{Portal frames}

The St-George's bridge was built in 1907 and replaced 2 bridges (Red Tower and Pas bridge). It allows crossing of the river Lys, near to the original confluence. Because of its replacing 2 former crossings, it has excessive width. Its vertical clearance of $3.5 \mathrm{~m}$ allows passing of smaller vessels to access the yacht-basin of Ghent, called 'Portus Ganda', a long-term development project of the city. The Cauldron bridge, built in 1912, crosses the canal, connecting rivers Lys and Scheldt, dug already in the $11^{\text {th }}$ century delimiting the medieval city to the South. It carries road traffic to 2 important squares of the city, the commercial centre and the old court of justice. The bridge is also crossed by the main tramway line of the city.

Both bridges are of an identical type of two-hinge steel portal frame. This allows minimum structural depth near the span centre and maximum vertical clearance for the subjacent waterway. Since both bridges were built at the same period, similarities are frequent and the largest one, StGeorge's bridge will be discussed more in detail.

The two-hinge portal frame of St-George's Bridge was designed, allowing a vertical rounding bend of $136 \mathrm{~m}$ in the road. This scheme is shown in Fig. 1. The designers have chosen to build the bridge considerably wider than strictly necessary. This also allowed a straight crossing of the portal frames with the river, thus obtaining minimum span length. In the past, the unnecessary areas of the bridge were used as parking places, whereas today the footpaths are extremely large, the road width being $13 \mathrm{~m}$ and the bridge's width equalling $35 \mathrm{~m}$.

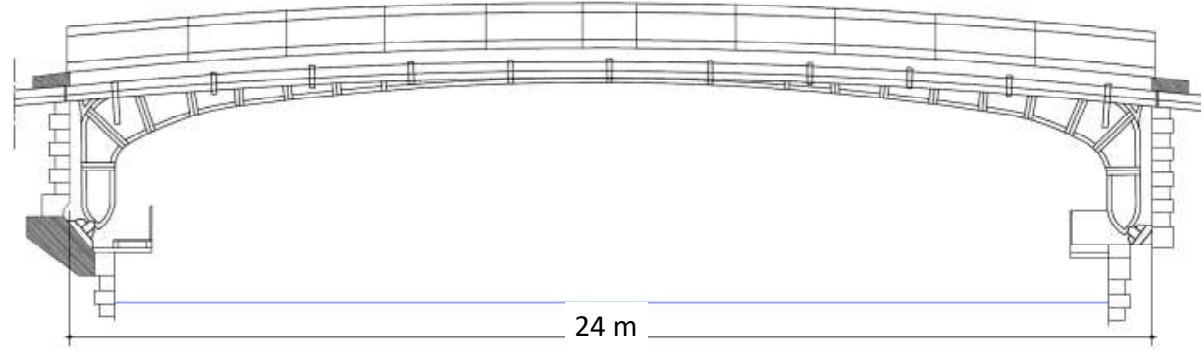

Fig. 1. Structural scheme St-George's Bridge

The number of supporting frames equals 23, of which 21 are identical and the left and right frames being slightly different, to support the railings. The frames are connected by 24 crossbeams, also connecting the vertical legs of the frames. These can be seen as the lines corresponding to the web plate stiffeners in Fig. 1. Although this bridge dates from 1907, the parallel ribs show similarity to recent bridges and coverings. The parallel frames clearly show variable beam depth, in accordance with the expected bending moment distribution. This depth is varying from $1.071 \mathrm{~m}$ to $0.356 \mathrm{~m}$ at mid-span. The web plate thickness does not vary, whereas the flanges are gradually reinforced (C) Ernst \& Sohn Verlag für Architektur und technische Wissenschaften GmbH \& Co. KG, Berlin · CE/papers (2017) 
towards the span centre. The entire structure is assembled by rivets of 20, 22 and $25 \mathrm{~mm}$ diameter. This has required extensive use of angular profiles, of types which today are no longer produced. The angles must have been bent with radius as low as $700 \mathrm{~mm}$. Some of the angle profiles, at the intersection of crossbeams are forged to avoid filling plates. All these details prove the craftsmanship of steel building at the beginning of the $20^{\text {th }}$ century and are a remarkable testimony of workmanship.

\subsection{Present Condition}

Both bridges have recently been inspected. The general aspect of both bridges is worrying and corrosion is seen in every detail. However, it is more important to find out whether the steel sections show considerable reduction and to quantify this. Although modern riverside walkways have been installed below both bridges, the corrosion protection has not been renewed since 30 years. For both bridges especially the outside frames are corroded, either the angle profiles or the lower flanges or the top plate of the upper flange. In a single case of a vertical frame post, the complete upper flange is corroded. This can be seen in Fig. 2 (left).
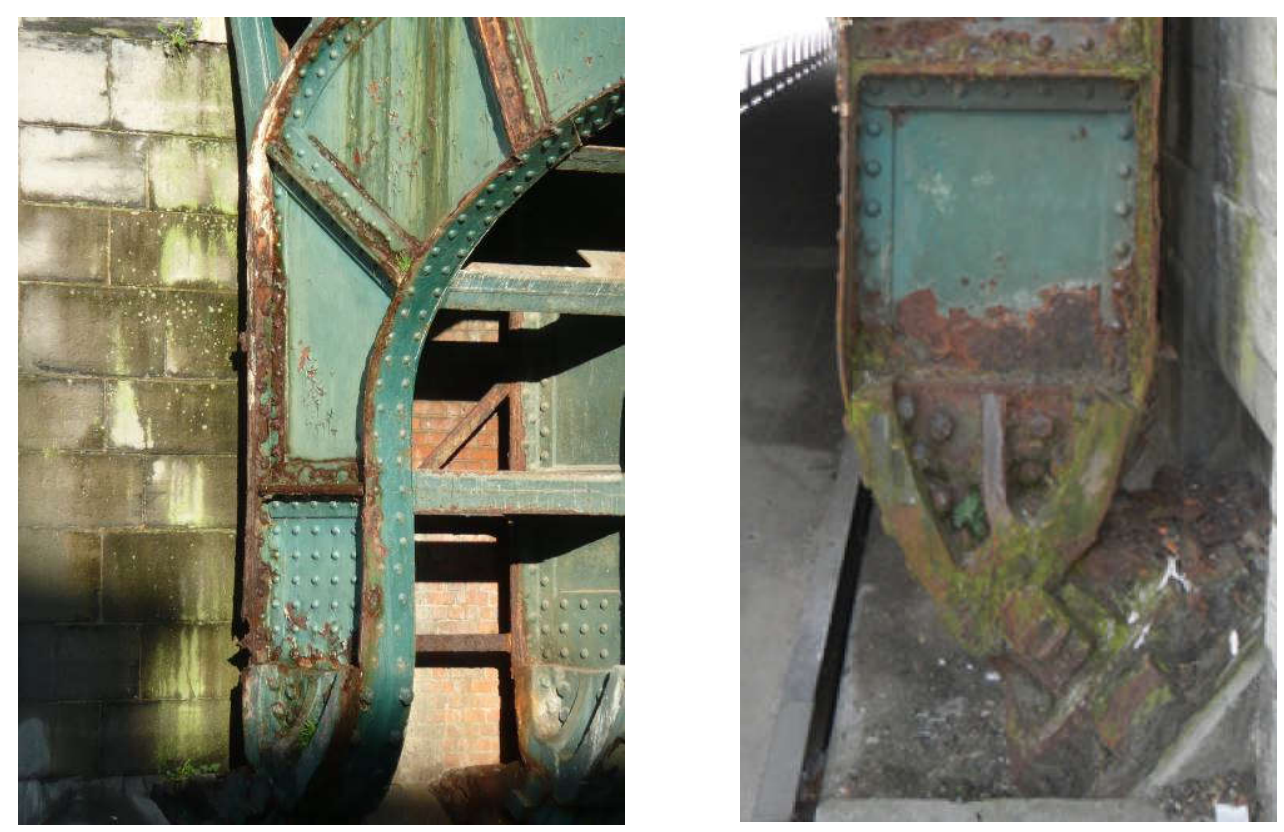

Fig. 2. Left : reduction of flange section Right : Corrosion of hinges

These observations have been supplemented at the most critical locations by grinding to blank metal and by measuring the exact length of the main corrosion areas. This enabled to derive exact data of the remaining profile and plate sections and to assemble characteristics of an alternative damaged structure. Superficial deterioration has not been considered in this alternative.

The hinged supports were inspected more in particular. Already Fig. 2 (right) shows a rather bad condition. However, after manual brushing, hammering and subsequent local grinding, the corrosion of these parts appeared equally superficial and limited to less than $1 \mathrm{~mm}$. Most probably the hinge is not functioning sufficiently and will require serious refurbishment.

\subsection{Load-carrying capacity}

The inspection and further observations have allowed to model the structures, including crosssectional weakening and at various locations, vanished flanges or webs. Obviously, these more than 100 year old structures were never designed according to requirements of present codes. The national annex to EN 1991-2 [3] recognizes this fact for bridges in urban environment and allows verification, using frequent load models, according to FLM 2. However, this has been supplemented by considering tramway loading as well as city buses [4]. The latter may include some axle loads up to $135 \mathrm{kN}$.

In addition, the horizontal forces from braking, acceleration and centrifugal force have been included, as well as the effects of temperature, both global and differential. However, the limits of 
walkways were taken from reality, meaning that in particular for St-George's Bridge, a large portion of the bridge is not available for road traffic. This part can very well be loaded by LM 5 or the effect of crowds.

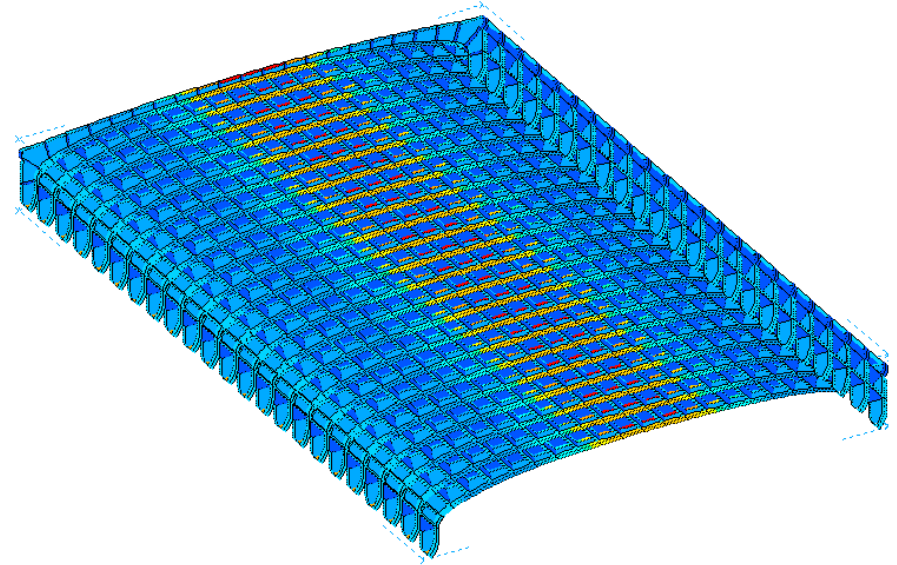

Fig. 3. Complete model used for portal frame bridge

The results, obtained through the use of the model from Fig. 3 show that the effect of concentrated force from loading models is but poorly distributed among the portal frames. This also applies to the crowd loading on the walkways. The easiest way to present the results of the load carrying capacity is by the unity-check of vonmises stresses compared to the factored design value of the yield stress as in Table 1.

\begin{tabular}{lcc}
\multicolumn{1}{c}{ Table 1. } & Unity checks of end frames St-George's Bridge \\
\hline Unity-check & North end frame & South end frame \\
\hline Span centre upper flange & 0.221 & 0.206 \\
Span centre lower flange & 0.551 & 0.361 \\
Frame node upper side & 0.949 & 0.530 \\
Frame node lower side & 1.251 & 1.091 \\
Post outside & 0.719 & 0.349 \\
Post inside & 0.940 & 0.772 \\
\hline
\end{tabular}

Obviously, both the Northern and Southern end frames do not comply with the requirements. The live load for this critical situation is crowd. However, this can be remediated by reducing considerably the walkways dead load, thus decreasing the total load. This has been explained in detail in [5]. In the former, some cross-section characteristics were exceptionally asymmetrical. This was particularly striking and appeared to be related to the weakening by rivet holes, discussed hereafter.

\section{RIVETED CROSS-SECTIONS}

\subsection{Asymmetrical character}

The cross-sectional characteristics of the frames are varying, according to the portal beam depth. In particular, near the span centre, the total depth is reduced at maximum, thus requiring reinforcement of the flanges by additional plates. The cross section characteristics are shown in Fig. $4 a$ for St George's bridges and Fig. 4b for the smaller Cauldron Bridge.

Obviously, at this location the upper flanges are compressed, whereas the lower flange is in tension. As the normal force has little influence, an important difference of areas is noticed. For the left part of Fig 4 the upper flange is $86 \%$ of the lower one, whereas for Fig. 5 right the difference equals $55 \%$. There must be a fundamental reason for the smaller compressed flanges. 
Clearly, adding plates to flanges, connected to the webs by angles angle profiles and rivets, does not increase linearly the resisting moment, since the rivet holes are weakening the area. The latter must be subtracted from the initial properties. In the case of Fig. $4 a$ the ratio of reduction equals up to $86 \%$ and if the corrosion is taken into account, even as much as $83 \%$. Hence, the reduction of resisting cross-sectional properties by holes may be of paramount importance.
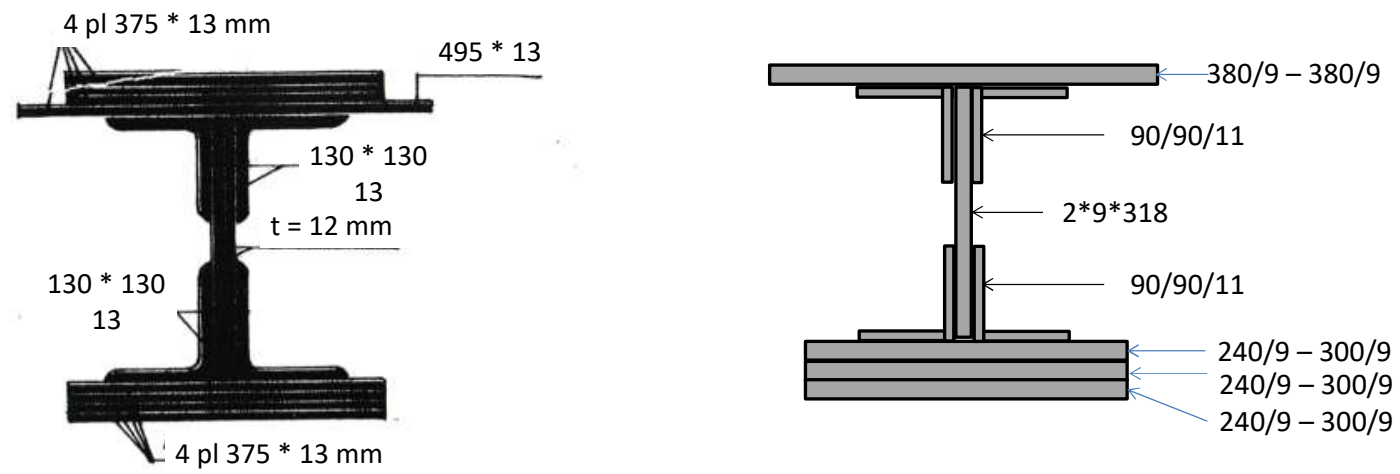

Fig. 4. a) Cross section span centre St George's Bridge; b) Id Cauldron bridge

Eurocode 3 part 1-8 [6] is rather silent about this, since it mainly applies to bolted connections. Nevertheless this standard may give a first indication, since the formula of table 3.4 uses a crosssection area $\mathrm{A}_{0}$ corresponding to the complete hole diameter. This indicates that the standard considers the hole to be filled completely. If the connection is compressed, this also implies that the gross section may be considered.

The need was felt to obtain more references before deciding. In [7] is stated that solid circular sections are used as compression members and are effective in resisting compression and no deduction must be made for rivet holes. In [8] was found that for compression members all bolt holes and openings other than rivet holes shall be deducted from the cross-sectional area, the case of rivets thus being excluded. This would also explain why the cross-sections of Fig. 4 are unsymmetrical. However, the fabrication of riveted joints includes heating and cooling of parts and plastic deformation. Hence, further justification of the mechanism is necessary.

\subsection{Rivet characteristics}

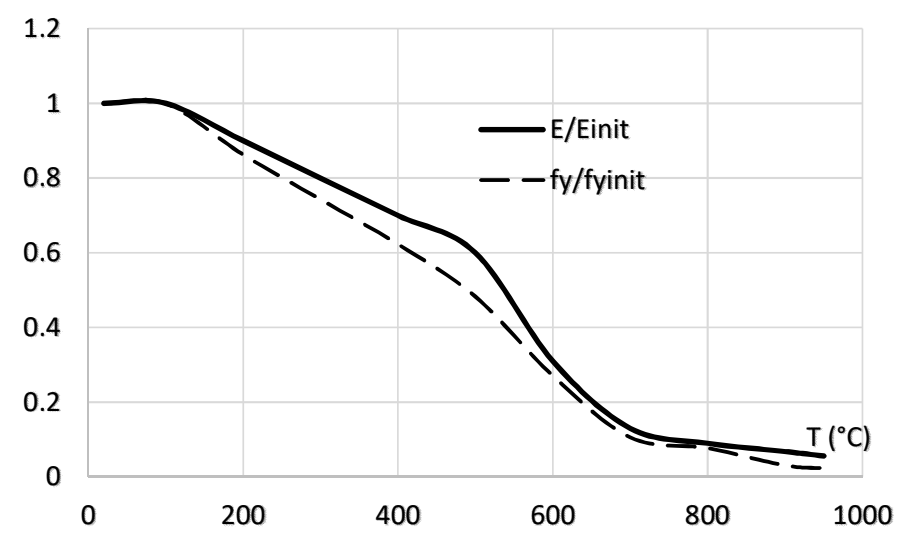

Fig. 5. Variation of modulus and yield stress with temperature

For most types of rivets, the hole diameter is $0.5 \mathrm{~mm}$ larger than the cold rivet itself. The rivet is heated up to $950^{\circ} \mathrm{C}$ (dark red colour) and subsequently placed in the hole. It is then forced and hammered to obtain the specific shape of the rivet head. Obviously, the hammering makes the hole completely filled. It is generally accepted that after hammering the rivet has cooled down to $600^{\circ} \mathrm{C}$. Further cooling introduces a tensile force in the direction of the rivet axis, thus provoking the well- 
known compression of the joint. This preloading was never really taken into account, since rivets were calculated for shear force.

To understand more exactly how the rivet characteristics are changing during the cooling process, Fig. 5 displays the variation of the modulus and yield stress of most steel products at higher temperature [9].

Already during warming, the ultimate strength of a rivet is exceeded and complete plastification is reached. In addition, the cooling process is more relevant to know to what extent the rivet holes are remaining filled and there should be no reduction of the gross section of joined plates.

\subsection{Cooling process}

The cooling process thus starts at a temperature of $600^{\circ} \mathrm{C}$. Obviously, the hammering of the rivet has also introduced radial stress in the rivet shaft. These stresses must first be relieved, before the shaft can shrink freely. Stress relief follows the dotted line of Fig. 6 instead of the full line for loading.

The radial stress at least equals the yield stress of $348 \mathrm{MPa}$ and results in the cylindrical strain of

$\varepsilon=f_{y} /(E(1-v)$

in this case equalling 0.001711 . In Fig. 5 this corresponds to lowering the temperature from $600^{\circ} \mathrm{C}$ to $453^{\circ}$. The latter also corresponds to values indicated by experienced persons, who were involved in last century in riveted bridge construction. After this decompression follows free shrinkage of the shaft and the strain can be found from expression (2).

$\varepsilon=\alpha \Delta T$

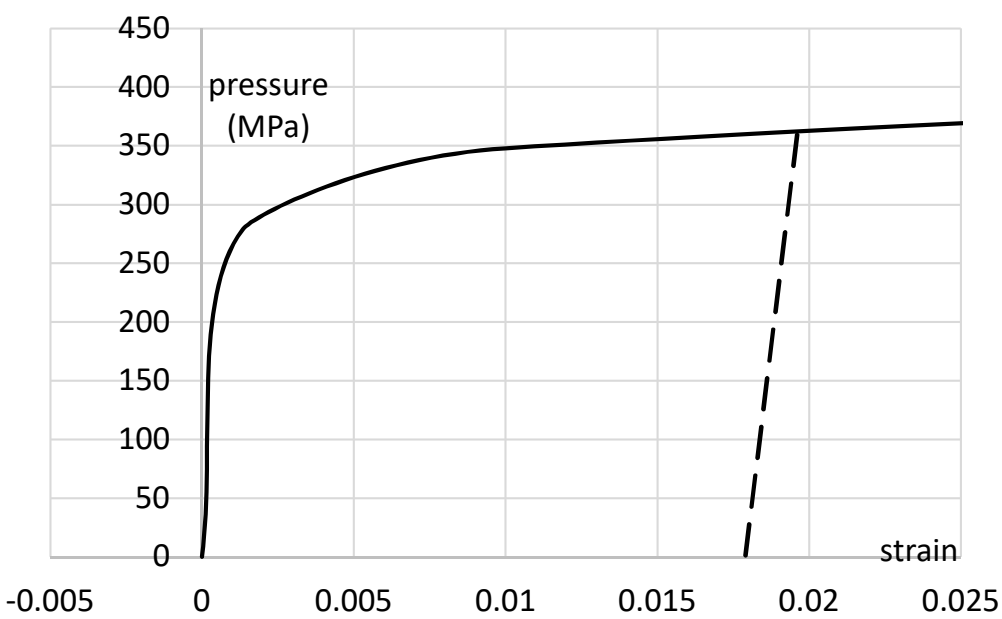

Fig. 6. Stress increase and relief of steel rivets

The results are found in Table 2, for those rivet diameters found in the structures aforementioned. Apart from the gap between the cooled rivet and the hole edge, the table also mentions gaps that are normally accepted for fitting bolts. The latter may be designed in compression, considering the entire area of plates, without subtracting the holes. In all cases the gaps are smaller than the fitting bolt tolerance.

Table 2. Hole gap for various rivet diameters after cooling

\begin{tabular}{lccc}
\hline rivet $D$ & 25 & 22 & 20 \\
\hline hole $D$ & 25.5 & 22.5 & 20.4 \\
shrinkage & 0.176 & 0.155 & 0.141 \\
fitt bolts & 0.3 & 0.2 & 0.2 \\
\hline
\end{tabular}

In addition, a simple model was made of a circular plate with hole of $25.5 \mathrm{~mm}$, containing a separate cylindrical shaft. At first, in Fig. 7a, the inner shaft is expanding during heating. When 
both bodies come in contact; a radial compression stress is introduced. In this model, no forced deformation of the rivet is included. At a temperature of $950^{\circ} \mathrm{C} \mathrm{Fig.} 7 a$ shows the contact stress, which does not exceed $251 \mathrm{MPa}$. This demonstrates the low expansion due to heating, although the yield stress has become extremely low. To the right Fig. $7 b$ shows the reverse process of a cooling cylinder. After loosing contact with the hole edges, the radial deformation is limited to $0.055 \mathrm{~mm}$, this figure being lower than the results of Table 2 .
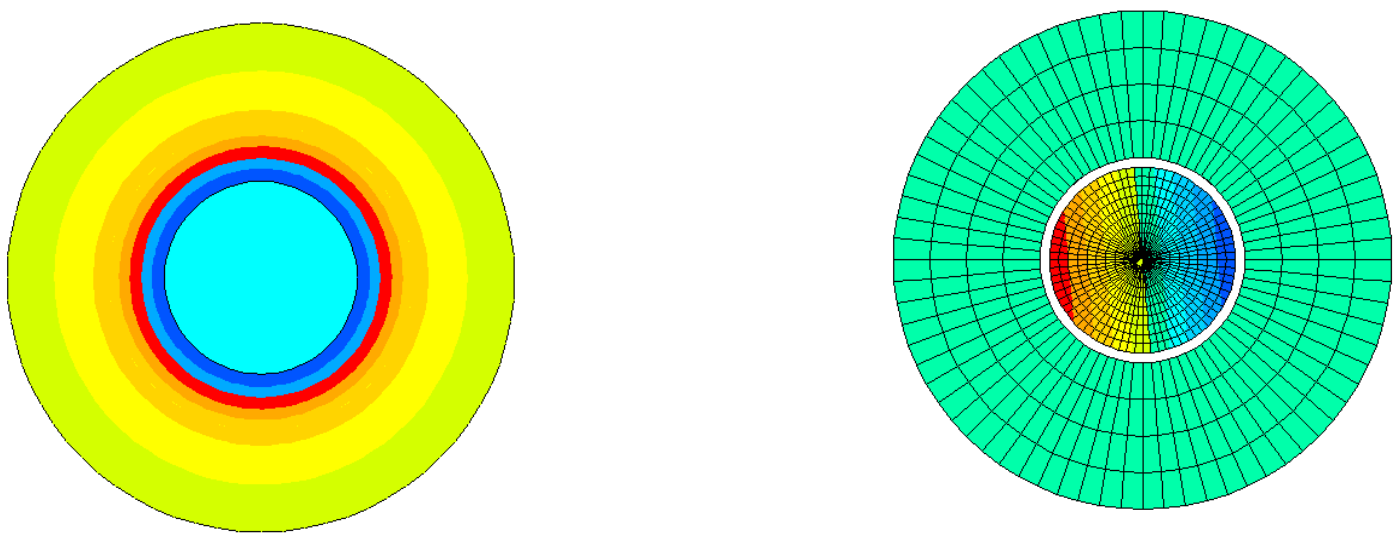

Fig. $7 a$ (left) Temperature increase contact stress $7 \mathrm{~b}$ (right) Cooling gap

\subsection{Damage to rivets}

In the 3 portal frame bridges, especially in the corroded ones, the upper rivet heads have completely corroded. However the rivets are still in place and did not fall out from the steel members. This further supports the assumption that the remaining parts of the shaft is fitting the hole.
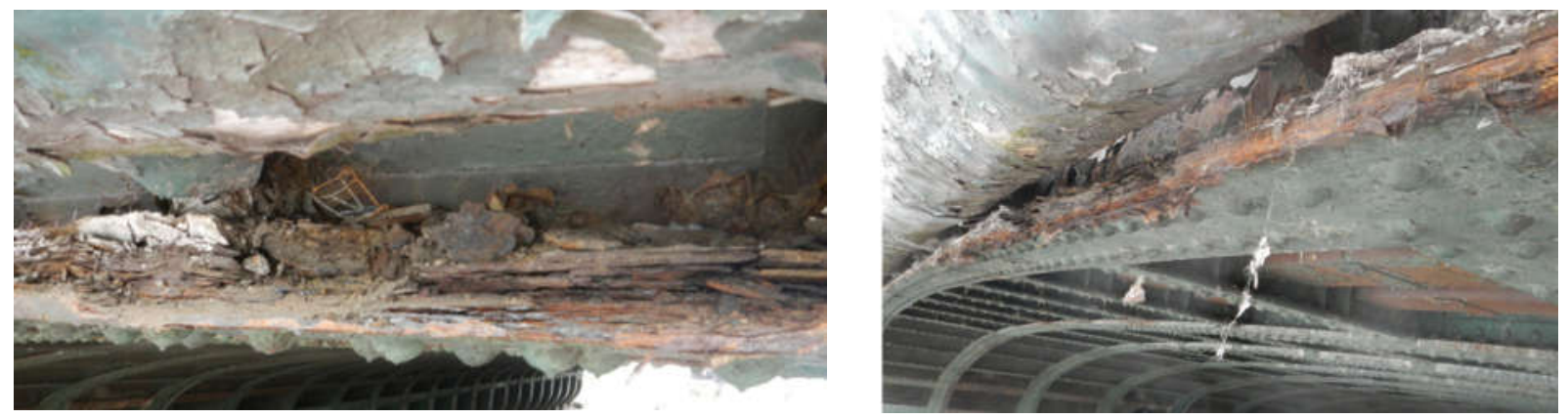

Fig. 8. Corroded rivets

Fortunately the rivets on the opposite side of this connection are in good condition. Since shear is moderate in this area, the connection remains effective, although near to the posts the unity-check of rivets results in a value of 0.897 .

\section{COMBINATION WITH CORROSION}

The last remark has made it interesting to evaluate the combined effects of weakening of crosssections and deduction of rivet holes. For the case of St-George's Bridge, which is the most heavily corroded, the values of the resisting moment have been derived for 4 conditions. The reference is the initial, not corroded condition. The initial condition with deduction of rivet holes, the damaged condition without holes and finally the corroded condition with deduction of holes, have been compared to the reference in Fig. 9.

Clearly, the reduction of the resisting moment capacity by holes takes a rather constant character, with small variations from 0.84 to 0.9 . Of course, the effect of corrosion varies according to the reduction of steel sections. The diagram shows reductions are largest at $3 \mathrm{~m}$ from the span centre, due to weakening of the lower flange, and at the frame node, due to corrosion of the upper flange. 
This corrosion pattern, chiefly appearing in the compressed parts, was fortunate, since reduction of holes was unnecessary. However, the diagram also shows that reduction by holes is more severe for the corroded sections.

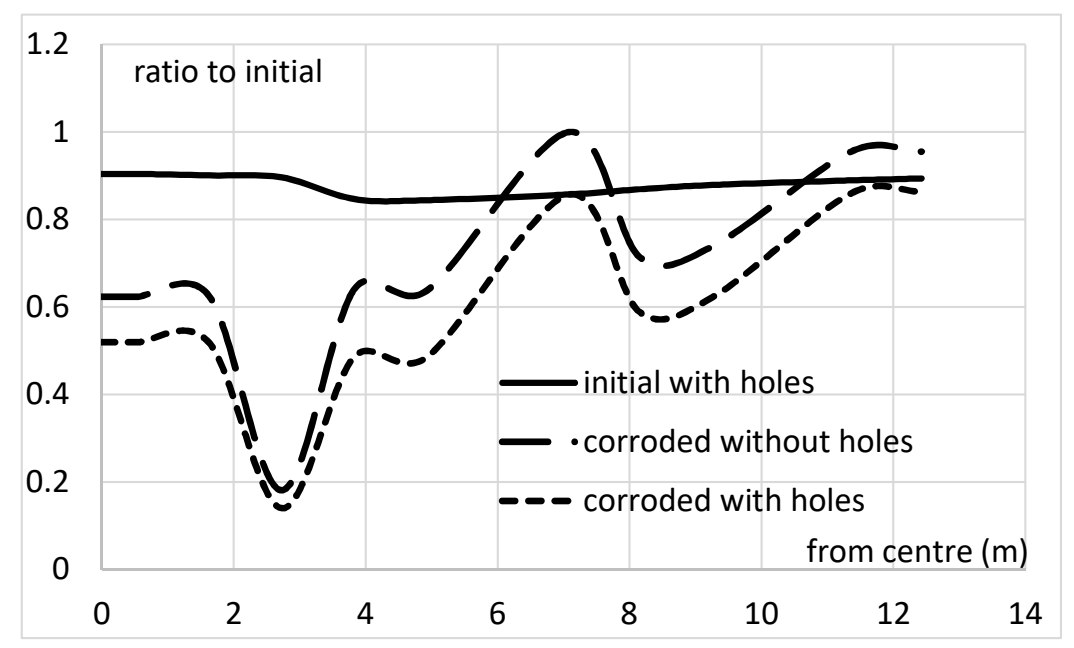

Fig. 9. Comparison of reduced sections

\section{REFERENCES}

[1] Simmel, G. "Brücke und Tür". Essays des Philosophen zur Geschichte, Religion, Kunst und Gesellschaft. De Tag K.F. Koehler Verlag Stuttgart 1957 Whitmore R.E. "Experimental investigation of stresses in gusset plates". Bulletin No. 16, Engineering Experiment Station, University of Tennessee, May, 1952

[2] Larsson, T., Lagerqvist, O., "Material properties of old steel bridges", Proceedings Nordic Steel Conference 2009 Malmö Sept 2-4 2009, pp 120-127

[3] EN 1991-2 Eurocode 1: Actions on structures - Part 2 : Traffic loads on bridges. CEN Sept 2003.

[4] Schoemaker, J. T., "Research on the weight of buses and touring coaches". Final report, International Road Transportation Union. NEA Rijswijk 2007.

[5] Van Bogaert, Ph., "Load carrying capacity of two 110-year old steel portal frame bridges". Proceedings 19th Congress of IABSE, Challenges in design and construction of an innovative and sustainable built environment. Stockholm Sept 2016 pp 600-607.

[6] EN 1993-1-8 Eurocode 3 : Design of steel structures - Part 1-8 : Design of joints. May 2005 + AC 2005

[7] Punmia, B.C., Jain, A.K., "Comprehensive design of Steel Structures”. Laxmi Publ - Delhi 1987

[8] Wardlaw G.A., "Standards and Specifications for Metals and Metal Products". US Government Printing Office 1933

[9] Outinen, J., Mäkeläinen, P., "Mechanical properties of structural steel at elevated temperatures and after cooling down", Proceedings of the 2nd International Workshop structures in Fire, Christchurch NZ 2002 pp 273-289 